\title{
Energetic consequences of plunge diving in gannets
}

\author{
Jonathan A. Green ${ }^{1,5, *}$, Craig R. White ${ }^{2,3}$, Ashley Bunce ${ }^{4,6}{ }^{\text {, Peter B. Frappell }}{ }^{1,7}$, \\ Patrick J. Butler ${ }^{2}$ \\ ${ }^{1}$ Adaptational and Evolutionary Respiratory Physiology, Department of Zoology, La Trobe University, Melbourne, \\ Victoria 3070, Australia \\ ${ }^{2}$ Centre for Ornithology, School of Biosciences, University of Birmingham, Edgbaston, Birmingham B15 2TT, UK \\ ${ }^{3}$ School of Integrative Biology, The University of Queensland, St Lucia, Queensland 4072, Australia \\ ${ }^{4}$ School of Ecology and Environment, Deakin University, 221 Burwood Highway, Burwood, Victoria 3125, Australia \\ ${ }^{5}$ Present address: School of Biological Sciences, University of Liverpool, Crown Street, Liverpool L69 7ZB, UK \\ ${ }^{6}$ Present address: Centre for Marine Studies, University of Queensland, St. Lucia, Queensland 4072, Australia \\ ${ }^{7}$ Present address: School of Zoology, University of Tasmania, Hobart, Tasmania 7001, Australia
}

\begin{abstract}
Seabirds that forage by plunge diving dive less frequently than those that dive from the water surface, and spend less time in flight than more generalist foragers. We hypothesised that this is due to foraging by plunge diving entailing a high energetic cost, which in turn is due to high energetic costs of take-off and flight. Using heart rate as a proxy for metabolic rate, we evaluated the energetic costs of foraging by plunge diving in the Australasian gannet Morus serrator. As expected, flight entailed a high energetic cost, and energy expenditure during foraging was equivalent to that during flight and significantly higher than that when animals were resting during foraging trips or were inactive on land. These values represent the highest costs of foraging yet recorded in a seabird, and the low frequency of plunge diving can be attributed to these high costs. On average, Australasian gannets perform 2.6 dives $\mathrm{h}^{-1}$ when foraging, with a mean dive duration of $3.4 \mathrm{~s}$. As a result, they spend $<0.25 \%$ of the duration of each foraging trip submerged. We combined this information with previously obtained data on diet to calculate an estimated rate of prey capture of $\sim 287 \mathrm{~g}$ $(\text { min submerged })^{-1}$. This rate is at least 7 times greater than rates recorded in other diving birds. For plunge divers, therefore, the high costs of foraging are offset by high rates of energy gain.
\end{abstract}

KEY WORDS: Energetics · Gannet · Plunge diving $\cdot$ Foraging $\cdot$ Catch per unit effort $\cdot$ CPUE

\section{INTRODUCTION}

Seabirds move between their foraging and breeding areas by swimming or using different modes of flight (e.g. flapping or gliding). Some species travel great distances from their nest sites (e.g. Berrow et al. 2000), others remain relatively close (e.g. Petersen et al. 2006) and some use a combination of long/ distant and short/local foraging trips (e.g. Chaurand $\&$ Weimerskirch 1994). During foraging, seabirds use a variety of methods to catch their prey, including dives from the surface to the bottom (e.g. Guillemette et al. 2004), pelagic dives from the surface powered by wings, flippers or feet to capture mobile or swarming prey (e.g. Sato et al. 2007), surface feeding (e.g. Catry et al. 2004), 'skimming' or surface feeding on the wing (e.g. Weimerskirch et al. 2004), and plunge diving (e.g. Ropert-Coudert et al. 2004b).

Studies on the physiology, ecology and behaviour of foraging in seabirds have focussed on dives from the water surface (surface diving) as performed by birds such as penguins, cormorants and auks. In contrast, despite its prevalence among groups of birds such as terns, gannets, boobies, gulls and shearwaters, very few studies have focussed on plunge div- 
ing. Compared to surface dives, plunge dives are very brief in duration and occur infrequently (Zavalaga et al. 2007). Plunge diving is thought to be associated with a very high probability of prey capture (>50\%, Wanless et al. 2005), and prey items caught tend to be relatively large (Bunce 2001). Surface divers tend to dive continuously during foraging periods, which may be explained through an examination of energetic costs. A common finding for surface divers from penguins (Green et al. 2002) to shags (Bevan et al. 1997, Enstipp et al. 2005) is that diving (including subsequent post-dive surface intervals) incurs no greater energetic cost than simply resting at the water surface during foraging trips. Therefore, seabirds which dive from the water surface do so nearly continuously during foraging trips in order to maximise their energy gain. On the other hand, more generalist seabirds that feed at the water surface (e.g. albatrosses and petrels) spend the majority of their foraging trips on the wing in dynamic soaring flight. Studies have shown that in these animals, the energetic cost of this dynamic soaring flight is low and similar to the energetic cost of foraging at the water surface (Bevan et al. 1995). As a result, they are able to maximise the time and area over which they can search for profitable food patches by spending much of their trips in flight. Conversely, plunge divers dive relatively infrequently (Zavalaga et al. 2007), spend an intermediate amount of time in flight, and spend much of their foraging trips resting at the water surface (Ropert-Coudert et al. 2004a). These distinctive foraging characteristics are independent of variation in prey fields and environmental conditions (Garthe et al. 2007). Plunge divers cannot gain energy if they do not take to the air before they dive, which suggests that there may be some constraint to the amount of time spent foraging by plunge diving. Might the benefits of plunge diving (high probability of prey capture and large size of captured prey) be offset by high energetic costs?

In the present study, we recorded the heart rates and diving behaviour of free-ranging Australasian gannets Morus serrator. We examined physiological adaptations for diving and used heart rate as a qualitative index of changing energy expenditure, to evaluate the costs of flight and foraging by plunge diving. We also combined our data with data obtained previously from the same population to establish a time budget during foraging trips. We aimed to (1) establish whether Australasian gannets dive at the low frequencies observed in other plunge divers, and (2) test the hypothesis that gannets perform relatively few plunge dives because foraging by plunge diving entails greater energetic costs than other modes of foraging.

\section{MATERIALS AND METHODS}

Heart rate $\left(f_{\mathrm{H}}\right)$ can be used to estimate the rate of oxygen consumption $\left(\dot{V}_{\mathrm{O}_{2}}\right)$, the latter being a proxy for metabolic rate (MR) if a calibration relationship is established between $f_{\mathrm{H}}$ and $\left(\dot{V}_{\mathrm{O}_{2}}\right)$ (e.g. Green et al. 2001). No such relationship exists for Australasian gannets so it is not possible to quantify the energetic costs of the different activities recorded in this study. However, increases in $f_{\mathrm{H}}$ above minimum levels may represent increases in $\left(\dot{V}_{\mathrm{O}_{2}}\right)$ (and hence in MR) as outlined by Fick's principle (Fick 1870, Butler 1993). The magnitude of changes in MR with respect to changes in $f_{\mathrm{H}}$ may vary as a result of (1) the shape and (2) the gradient of the relationship. Relationships between $f_{\mathrm{H}}$ and MR in birds may be linear (e.g. Green et al. 2001), curvilinear (e.g. Bevan et al. 1994) or possibly even exponential (e.g. Ward et al. 2002). However, it is incorrect to assume, as some authors have (e.g. Weimerskirch et al. 2001), that an increase in $f_{\mathrm{H}}$ above resting levels will result in a proportional increase in MR. This would only occur if the calibration relationship between $f_{\mathrm{H}}$ and MR were linear with an intercept of 0 , which is a calibration relationship that has yet to be described. Future work should attempt to determine the relationship between $f_{\mathrm{H}}$ and $\dot{V}_{\mathrm{O}_{2}}$ for gannets; in the absence of such a relationship, energetic costs in the present study are discussed qualitatively rather than quantitatively, by examining similarities and differences in $f_{\mathrm{H}}$.

The study was undertaken during the 2004-2005 breeding period of Australasian gannets at Pope's Eye Marine Reserve $\left(38^{\circ} 16^{\prime} 36^{\prime \prime} \mathrm{S}, 144^{\circ} 41^{\prime} 55^{\prime \prime} \mathrm{E}\right)$, which is located off Queenscliff near the entrance to Port Phillip Bay, Australia. All experiments were carried out with the approval of the La Trobe University Animal Ethics Committee (AEC 04/37L) and appropriate wildlife permits issued by Parks Victoria. This study site is monitored intensively, the monitoring program including monitoring of breeding success and productivity, a chick-ringing programme and determination of gender from observations of behaviour. Six mature breeding adults were selected randomly (mean mass $\pm \mathrm{SEM}=$ $2.58 \pm 0.05 \mathrm{~kg})$. The age (mean $\pm \mathrm{SEM}=14 \pm 3 \mathrm{yr})$ and gender (4 male, 1 female, 1 of unknown gender) of the birds were retrieved from the monitoring program data. The gannets were implanted with a custom-built data logger (DL) which recorded $f_{\mathrm{H}}$ and depth, as used in other diving seabirds, including gannets (e.g. Green et al. 2002, Grémillet et al. 2005, 2008). The DLs $(61 \times 24 \times$ $6 \mathrm{~mm}, 27 \mathrm{~g}_{i} \sim 1 \%$ of the body mass of adult Australasian gannets) had $4 \mathrm{MB}$ of memory and were programmed to store $f_{\mathrm{H}}$ and depth (with a resolution of $0.02 \mathrm{~m}$ ) every second. These data loggers have previously been shown to have no effect on the survival, behaviour and 
reproductive success of similar sized seabirds including common eiders Somateria mollissima (Guillemette et al. 2002) and macaroni penguins Eudyptes chrysolophus (Green et al. 2004). After programming, the loggers were encapsulated in wax and coated with silicone for biocompatibility. Prior to implantation, the loggers were bathed in a cold sterilising solution for $2 \mathrm{~h}$, and rinsed thoroughly with sterile water.

Surgical procedure. The implantations were performed on 15 and 16 September 2004, 5 to $10 \mathrm{~d}$ after egg laying, so that the birds were settled on their eggs and sufficiently motivated to continue incubating despite the potential for disturbance caused by handling and implantation. Each bird was captured by hand and removed together with its egg. The egg was immediately placed in a portable incubator at $38^{\circ} \mathrm{C}$ until the surgical procedure was completed, when both the adult and its egg were returned to the nest. A cardboard box $(\sim 45 \times 60 \times 30 \mathrm{~cm})$ was placed over the nest following removal of the bird and its egg in order to protect the bird's nesting territory during the surgery.

The birds were transported in pet packs by boat to a field station where the data loggers were implanted. The trip took $\sim 25$ to $30 \mathrm{~min}$. The surgical procedures for the implantations were as described by Stephenson et al. (1986). After the surgery, the bird, still asleep, was placed back in its pet pack and allowed to recover fully from the anaesthetic (usually 1 to $2 \mathrm{~h}$ ) before being returned to the colony. The entire procedure from the initial removal of the bird from the nest until its return took 3 to $4 \mathrm{~h}$. Once the bird had been returned to the nest, its egg was returned and the bird monitored for 4 to $5 \mathrm{~h}$. The birds were then checked approx. twice weekly for the duration of the breeding period to monitor their breeding status. Near the end of the breeding period and prior to chick fledging, implanted birds were recaptured at the nest and transported to the field station for the removal of the logger. The procedures for the removal of the logger and replacement of the bird in the colony after surgery were similar to those described for implantation. All 6 data loggers were retrieved and ran for the duration of the breeding season $(\sim 155 \mathrm{~d})$, with the exception of one (\#292) which stopped after $30 \mathrm{~d}$. Two of the DLs (\#244, \#110) had faulty pressure sensors and therefore provided no depth data; hence, data from the animals to which they were attached were not included in analyses. Thus, all 4 animals analysed were male.

Identification of behaviours for $\boldsymbol{f}_{\mathbf{H}}$ analyses. When deploying the DLs, we assumed that it would be possible to categorise the behaviour of the animals at all times throughout the deployment period using the $f_{\mathrm{H}}$ and depth data alone, as in previous similar studies (e.g. Grémillet et al. 2005, 2008, Pelletier et al. 2007). However, preliminary visual inspection of the data revealed that while some behaviours (e.g. flight) could easily be identified, there were other periods where we could not be certain in classifying behaviour, particularly when birds were resting on land or at sea. Thus, rather than risk error in our conclusions by making unsupported assumptions about behaviour, our analysis instead focussed on identifying periods where we could be confident about what the gannets were doing, while ignoring uncertain periods.

Dives could also be easily identified, but noise in the depth trace (which varied among the gannets as a function of their individual diving behaviour) meant that dives could only be detected reliably when they reached a depth $>0.5 \mathrm{~m}$ (\#135, \#292, \#112) or $1.5 \mathrm{~m}$ (\#535). Periods of foraging were identified from diving activity. Five key behaviours were identified and categorised using changes in $f_{\mathrm{H}}$ following initial inspection of the data, as described in reports of similar studies (e.g. Grémillet et al. 2005, 2008, Pelletier et al. 2007). These behaviours include:

(1) Flight: 5 min running averages of $f_{\mathrm{H}}$ were calculated for each second of each day. Flight was considered to have occurred when this 5 min average $f_{\mathrm{H}}$ was greater than a 'flight threshold' value for at least $20 \mathrm{~s}$ and no dives were detected. Flight $f_{\mathrm{H}}$ was then calculated as the average $f_{\mathrm{H}}$ during the $>20 \mathrm{~s}$ period when the running average was greater than the flight threshold. To select the flight threshold value, a range of threshold $f_{\mathrm{H}}$ values between 160 and 360 beats min $^{-1}$ were tested for each individual bird. We then plotted daily flight time as a function of threshold $f_{\mathrm{H}}$. Daily flight time decreased with increasing threshold, but in each case, there was a point of inflection where this decrease decelerated, indicating that the appropriate threshold (where $f_{\mathrm{H}}$ rapidly increased due to flight) had been identified. For example, for Bird \#112, below 240 beats $\min ^{-1}$, a 20 beats $\min ^{-1}$ change in threshold $f_{\mathrm{H}}$ resulted in a $2 \mathrm{~h}$ change in total daily flight time, whereas the same change in threshold above 240 beats $\mathrm{min}^{-1}$ resulted in a $0.5 \mathrm{~h}$ change in total daily flight time. The flight threshold was either $220(\# 135,535)$ or $240(\# 112, \# 292)$ beats $\mathrm{min}^{-1}$. Because flight $f_{\mathrm{H}}$ was calculated for a period $>20 \mathrm{~s}$, but was identified based on a $300 \mathrm{~s}$ running average, it was possible for flights $<20 \mathrm{~s}$ to have a mean $f_{\mathrm{H}}$ that was less than the flight threshold value. Conversely, all flights $>300$ s were essentially constrained to a minimum of the flight threshold value. However, this had only a minor influence on the calculated value of flight $f_{\mathrm{H}}$, since flight $f_{\mathrm{H}}$ of flights $<300 \mathrm{~s}$ differed from flights $>300 \mathrm{~s}$ by only $<5 \%\left(17\right.$ beats $\left.\mathrm{min}^{-1}\right)$.

(2) Take-off: the highest $20 \mathrm{~s}$ average $f_{\mathrm{H}}$ during the initial part of flight.

(3) Foraging: a period where multiple dives were separated by $\leq 1 \mathrm{~min}$. Foraging $f_{\mathrm{H}}$ was then calculated by averaging $f_{\mathrm{H}}$ over a period beginning $5 \mathrm{~min}$ before the 
first dive and ending 5 min after the last one. This time period was developed through iteration to include flight prior to plunge dives, and take-offs which occurred immediately after dives.

(4) Resting during foraging: mean $f_{\mathrm{H}}$ was calculated every 5 min for each resting period between a foraging period and the succeeding foraging period or flight. The lowest of these values of mean $f_{\mathrm{H}}$ was assumed to represent resting during foraging. During these resting periods, the birds were probably resting on the water surface, but may have also been on rocks or other structures. Only resting periods between 30 and 180 min were considered, because $f_{\mathrm{H}}$ and duration of resting period were negatively correlated for durations $<30 \mathrm{~min}$ (presumably because the animals were not resting), and for durations $>180 \mathrm{~min}$ (because the animals were assumed to have completed foraging). Less than $13 \%$ of periods which could have been classified as 'resting during foraging' exceeded $180 \mathrm{~min}$.

(5) Inactive resting: the lowest 5 min mean $f_{\mathrm{H}}$ which occurred between midnight and the first flight of each day. This time period was chosen as other studies of diurnal foraging by free-ranging seabirds have shown this to be the period of minimum $f_{\mathrm{H}}$ (e.g. Green et al. 2002).

Diving analysis. The duration and maximum depth of each dive were extracted and the median, mode and mean of these quantities calculated for each individual. Dives were classified by duration. Mean depth and $f_{\mathrm{H}}$ were calculated for each animal for each second of each dive duration category as well as each second for $45 \mathrm{~s}$ before and after each dive.

Time budgets. We were unable to establish the exact timing and duration of foraging trips by analysis of the DL data alone, as it was not possible to be sure of what the birds were doing at all times. The time spent submerged during diving and in flight was calculated for each bird for each day of the deployment, since we could be confident in identifying these behaviours. Birds undertook flights on $99 \%$ of the days and dives on $94 \%$ of the days of the study period. To establish a full time budget for our study animals, we combined our data with data on foraging trip duration from a radio-tracking study of this population (Bunce 2001). During the 1999-2000 breeding season, gannets from Pope's Eye spent $42.4 \%$ of each day $(10.2 \mathrm{~h})$ foraging away from the colony (Bunce 2001). The proportion of each day spent foraging did not vary between the incubation and chick-rearing phases (Bunce 2001). Thus, daily dive rate was converted to hourly dive rate during foraging trips using this value, as was the proportion of time spent submerged and in flight during foraging trips. Time in foraging trips not spent either in flight or submerged during dives was classified as resting during foraging (presumably at the water surface) to allow comparison with similar studies (e.g. Ropert-Coudert et al. 2004a).

Statistical analyses. Mean $f_{\mathrm{H}}$ during the various activities were compared using repeated measures (RM) ANOVA, and significant pairwise differences were identified with Tukey's HSD test. The effect of dive duration on the mean minimum $f_{\mathrm{H}}$ during a dive was examined using linear regression, which was weighted with the inverse of the SEM of the mean minimum $f_{\mathrm{H}}$. Dive duration was log-transformed for this analysis. Changes in $f_{\mathrm{H}}$ within dives were also examined. As time-points within a dive and dives within a bird are time-dependent, the changes in $f_{\mathrm{H}}$ which occurred during diving were assessed using a general linear mixed model (GLMM) with time as a fixed ordinal factor and bird ID and dive number (\#, nested within bird ID) as random nominal factors (see Krueger \& Tian 2004 for a comparison of GLMM and RM methods for the analysis of longitudinal data). $\alpha$ was set at 0.05 for all comparisons. Thus, any statement indicating the presence or absence of a difference between 2 mean values is based on these statistical analyses. Data were not pooled, thus the mean values presented are the grand mean (mean of means) of the 4 ind. analysed and are presented \pm SEM. All analyses were conducted using JMP IN v4.0.4.

\section{RESULTS}

All 6 birds implanted with DLs bred normally during the 2004-2005 season. Four fledged chicks while the fifth failed during incubation and the sixth during chick-rearing. Of the other 173 breeding attempts at Pope's Eye in 2004-2005, 23.1\% failed during incubation, $23.7 \%$ failed during chick-rearing and $53.2 \%$ survived to fledging. With these data, we have no reason to believe that our study animals were negatively affected by the implantation of the DLs. As described in 'Materials and methods', reliable data were obtained from 4 ind. Fig. 1 shows a typical sequence of $f_{\mathrm{H}}$ and diving behaviour of one of the birds over a $14 \mathrm{~h}$ period. While periods where behaviours were unambiguously identified are indicated, it was not so easy to use $f_{\mathrm{H}}$ data alone to determine behaviour throughout the deployment. For example, early in the morning, the bird was inactive, presumably resting on land, as $f_{\mathrm{H}}$ was low and steady. The bird then flew out to sea and during the day performed bouts of foraging activity, which were interspersed with periods of resting during foraging and flight. However, at the end of the day it was not possible to be sure whether the bird returned to the breeding colony or remained at sea. After determining the time budget for the gannets, we calculated 


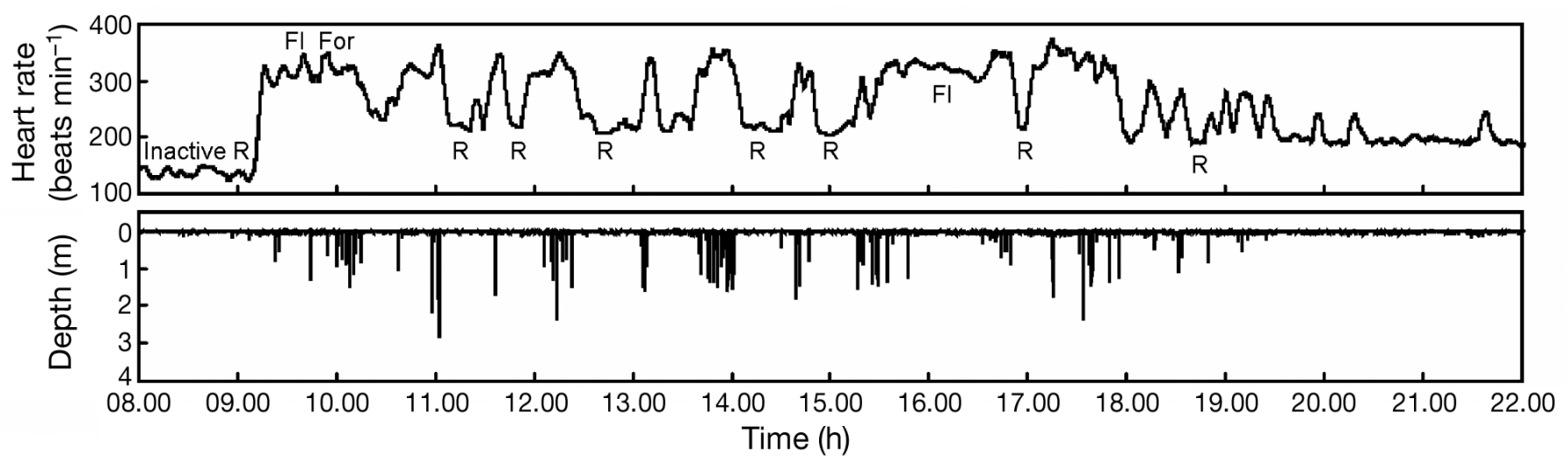

Fig. 1. Morus serrator. An example trace showing the heart rate (upper panel, smoothed with a running 5 min mean) and dive depth (lower panel) for Australasian gannet \#135. Example periods when behaviours were unambiguously determined as flight

(Fl), foraging (For), inactive resting (Inactive $\mathrm{R}$ ) and resting during foraging $(\mathrm{R})$ are indicated

that during foraging trips, the birds spent on average $48.1 \pm 8.3,0.23 \pm 0.06$ and $51.7 \pm 8.3 \%$ of their time in flight, being submerged and resting during foraging (presumably at the water surface), respectively. Dive rate during foraging was $2.6 \pm 0.7$ dives $h^{-1}$.

The mean number of times that each category of activity was detected and the mean $f_{\mathrm{H}}$ associated with that activity are shown in Table 1. RM ANOVA revealed differences in $f_{\mathrm{H}}$ among activities (RM ANOVA $\left.F_{5,23}=33.4, \mathrm{p}<0.001\right)$. There was no difference in $f_{\mathrm{H}}$ and hence in energetic costs between sustained flight and foraging. Minimum $f_{\mathrm{H}}$ during diving was not significantly different from that when the birds were resting during foraging. $f_{\mathrm{H}}$ during foraging was significantly greater than that while resting during foraging. $f_{\mathrm{H}}$ during take-off was significantly greater than that during sustained flight but not significantly different from that during foraging. $f_{\mathrm{H}}$ while resting during foraging was significantly higher than that during inactive resting.

There was considerable variation among individuals in the frequency and depth of dives (Table 2). Although the birds could dive to over $20 \mathrm{~m}$ and all remained submerged for over $30 \mathrm{~s}$, they routinely dived less deep than this, and $95 \%$ of the dives were on average $<6 \mathrm{~s}$ in duration (Table 2 , Fig. 2). Despite the relatively short duration of the dives, there was a clear and significant decrease in $f_{\mathrm{H}}$ during periods of submersion (RM ANOVA $F_{15,855}=32.0, \mathrm{p}<$ 0.0001). Also, the mean minimum $f_{\mathrm{H}}$ during dives decreased significantly as a function of dive duration (weighted regression $F_{1,31}=$ 346, $\mathrm{p}<0.0001$, Fig. 2). Mean minimum $f_{\mathrm{H}}$ during longer dives reached levels lower than inactive resting $f_{\mathrm{H}}$, but since the majority of dives were of short duration, the mean
Table 1. Morus serrator. Activity-specific grand mean (mean of means) heart rates $( \pm$ SEM) of 4 free-ranging Australasian gannets. There was significant variation in heart rate (RM ANOVA $\left.F_{5,23}=47.8, \mathrm{p}<0.001\right)$ among activities. Heart rates of activities superscripted with different letters are significantly different (Tukey's HSD, $\alpha=0.05)$. n: mean $( \pm$ SEM) number of occasions when each of the activities was recorded in the 4 birds

\begin{tabular}{|lcrccc|}
\hline \multirow{2}{*}{ Activity } & \multicolumn{2}{c}{$\begin{array}{c}\text { Heart rate } \\
\text { (beats } \text { min }^{-1} \text { ) }\end{array}$} & Mean & SEM \\
& Mean & SEM & & \\
\hline Inactive resting & $124.6^{\mathrm{a}}$ & 8.6 & 142 & 43 \\
Dive minimum & $231.1^{\mathrm{b}}$ & 15.9 & 4504 & 2136 \\
Resting during foraging & $233.5^{\mathrm{b}}$ & 14.6 & 184 & 138 \\
Flight & $281.4^{\mathrm{b}, \mathrm{c}}$ & 0.9 & 3067 & 962 \\
Foraging & $309.1^{\mathrm{c}, \mathrm{d}}$ & 22.2 & 1787 & 999 \\
Take-off & $354.4^{\mathrm{d}}$ & 6.0 & 3067 & 962 \\
\hline
\end{tabular}

Table 2. Morus serrator. Dive characteristics of 4 free-ranging Australasian gannets

\begin{tabular}{|c|c|c|c|c|c|}
\hline & \multicolumn{4}{|c|}{ Individual \# } & \multirow[t]{2}{*}{ Mean \pm SEM } \\
\hline & 112 & 135 & 292 & 535 & \\
\hline No. of days & 238 & 132 & 23 & 145 & $134 \pm 38$ \\
\hline No. of dives & 10417 & 3477 & 220 & 3902 & $4504 \pm 2136$ \\
\hline Dives $\mathrm{d}^{-1}$ & 44 & 26 & 10 & 27 & $27 \pm 7.0$ \\
\hline \multicolumn{6}{|l|}{ Depth (m) } \\
\hline Mean & 1.9 & 1.3 & 1.2 & 3.3 & $1.9 \pm 0.5$ \\
\hline Mode & 0.5 & 1.0 & 0.5 & 2.7 & $1.2 \pm 0.5$ \\
\hline Median & 0.8 & 1.1 & 1.1 & 2.9 & $1.5 \pm 0.5$ \\
\hline 95th percentile & 6.2 & 2.7 & 1.9 & 5.9 & $4.1 \pm 1.1$ \\
\hline Maximum & 23.0 & 14.0 & 2.4 & 21.8 & $15.3 \pm 4.7$ \\
\hline \multicolumn{6}{|l|}{ Duration (s) } \\
\hline Mean & 2.9 & 3.7 & 3.0 & 4.2 & $3.4 \pm 0.3$ \\
\hline Mode & 1 & 3 & 3 & 3 & $2.5 \pm 0.5$ \\
\hline Median & 2 & 3 & 3 & 3 & $2.8 \pm 0.2$ \\
\hline 95th percentile & 7 & 9 & 6 & 7 & $7.3 \pm 0.6$ \\
\hline Maximum & 34 & 32 & 42 & 33 & $35.3 \pm 2.3$ \\
\hline
\end{tabular}




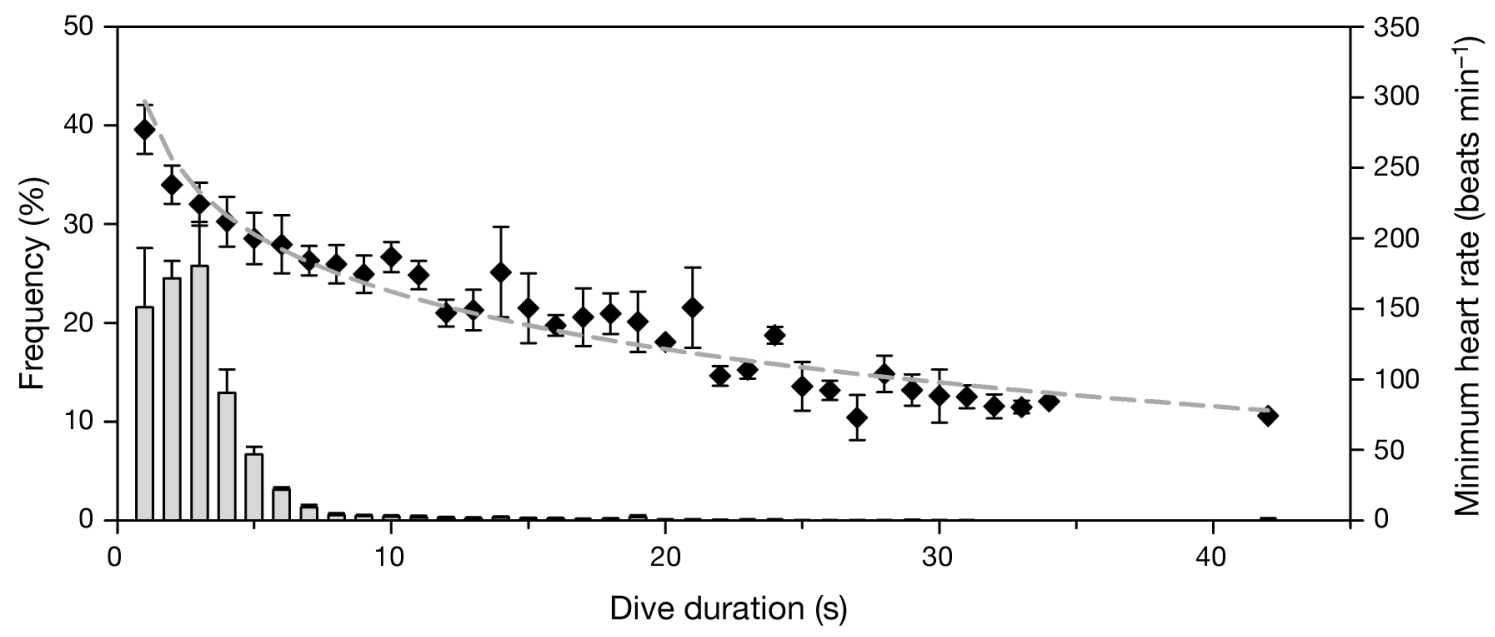

Fig. 2. Morus serrator. Frequency distribution of dive duration (grey bars) in 4 Australasian gannets. Also shown is the minimum heart rate $(\diamond)$ as a function of dive duration. Mean minimum heart rate $\left(\min f_{\mathrm{H}}\right)$ decreased significantly as a function of dive duration (grey dashed line) $\left(\min f_{\mathrm{H}}=297-58.8 \times \ln\right.$ (dive duration), $\left.\mathrm{r}^{2}=0.91, \mathrm{p}<0.001\right)$. All data are means $\pm \mathrm{SEM}$

minimum $f_{\mathrm{H}}$ was usually closer to $f_{\mathrm{H}}$ when the birds were resting during foraging (Fig. 2). Closer examination of $f_{\mathrm{H}}$ during dives revealed an interesting pattern of change during dives (see Fig. 3 for example). In all but the shortest dives ( $<3 \mathrm{~s}$ duration), $f_{\mathrm{H}}$ increased in the middle of the dive following the initial, relatively slow,
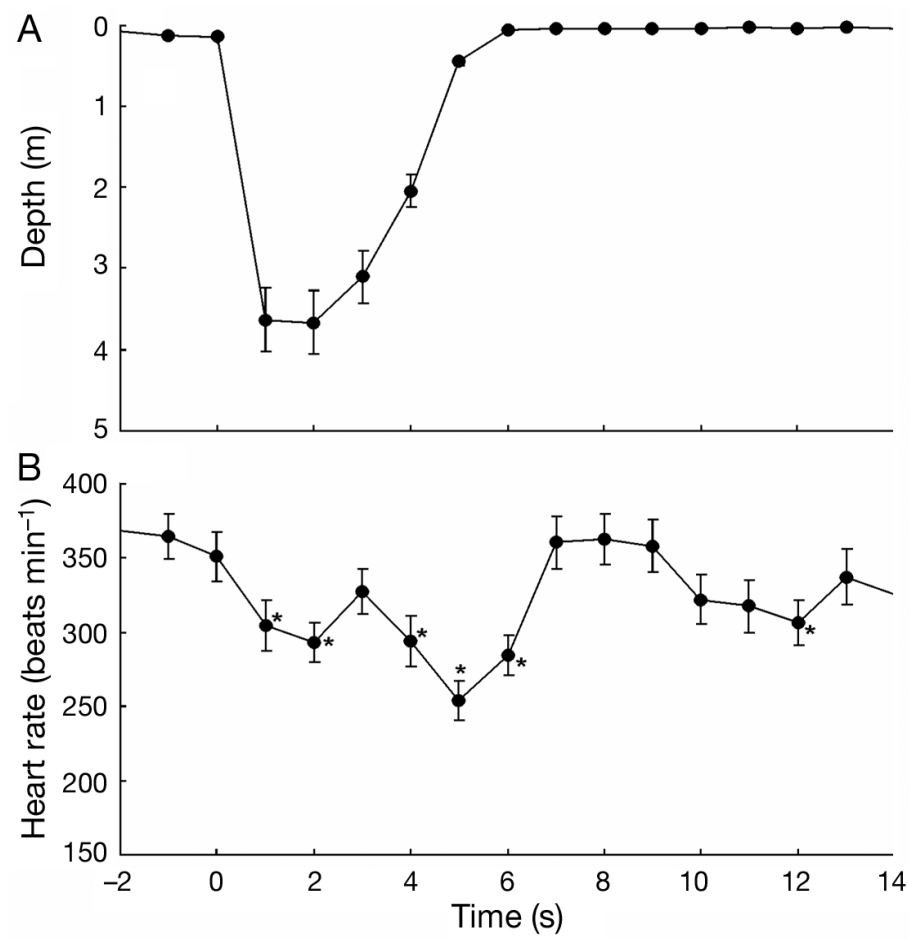

Fig. 3. Morus serrator. An example of the changes in heart rate during diving in Australasian gannets. (A) Mean dive depth and (B) heart rate were extracted for Gannet \#535 during 20 dives with a duration of $6 \mathrm{~s}$. Data are means \pm SEM. $(*)$ Values of $f_{\mathrm{H}}$ that are significantly different from pre-dive $(-2 \mathrm{~s})$ values (Tukey's HSD) decline (Fig. 3). In this example (20 dives of $6 \mathrm{~s}$ duration by Bird \#535), $f_{\mathrm{H}}$ was significantly lower than pre-dive $(-2 \mathrm{~s})$ values for periods of 1 to $6 \mathrm{~s}$ and $>10 \mathrm{~s}$ (Tukey's HSD). Although the increase in $f_{\mathrm{H}}$ occurred at the beginning of the ascent phase, it was followed by a further decline which was only terminated when the bird reached the surface. $f_{\mathrm{H}}$ then returned to the pre-dive level when the bird was at the surface.

\section{DISCUSSION}

\section{Energetic costs of foraging by plunge diving}

$f_{\mathrm{H}}$, and therefore energy expenditure, during foraging in Australasian gannets was not significantly different from that during flight but was significantly greater than the $f_{\mathrm{H}}$ while resting during foraging (Table 1). To interpret this finding fully, it is interesting to contrast it with findings from similar studies of $f_{\mathrm{H}}$ in free ranging seabirds (Fig. 4). In these other studies, behaviours were not necessarily defined in exactly the same way as in the present study, but they allow a broad comparison. In the similar sized South Georgia shag Phalacrocorax georgianus, $f_{\mathrm{H}}$ during foraging (dive cycles) was similar to $f_{\mathrm{H}}$ while resting on water but substantially less than $f_{\mathrm{H}}$ during flight (Fig. 4). South Georgia shags dive up to 100 times $^{-1}$ but spend $<6 \%$ of each foraging trip in flight (Wanless et al. 1995). In the larger black-browed albatross Thalassarche melanophrys, time spent at the water surface was assumed to represent time spent foraging, and resting during foraging was not defined. In this species, $f_{\mathrm{H}}$ during flight and foraging were very similar, and both increased when compared to $f_{\mathrm{H}}$ during inac- 


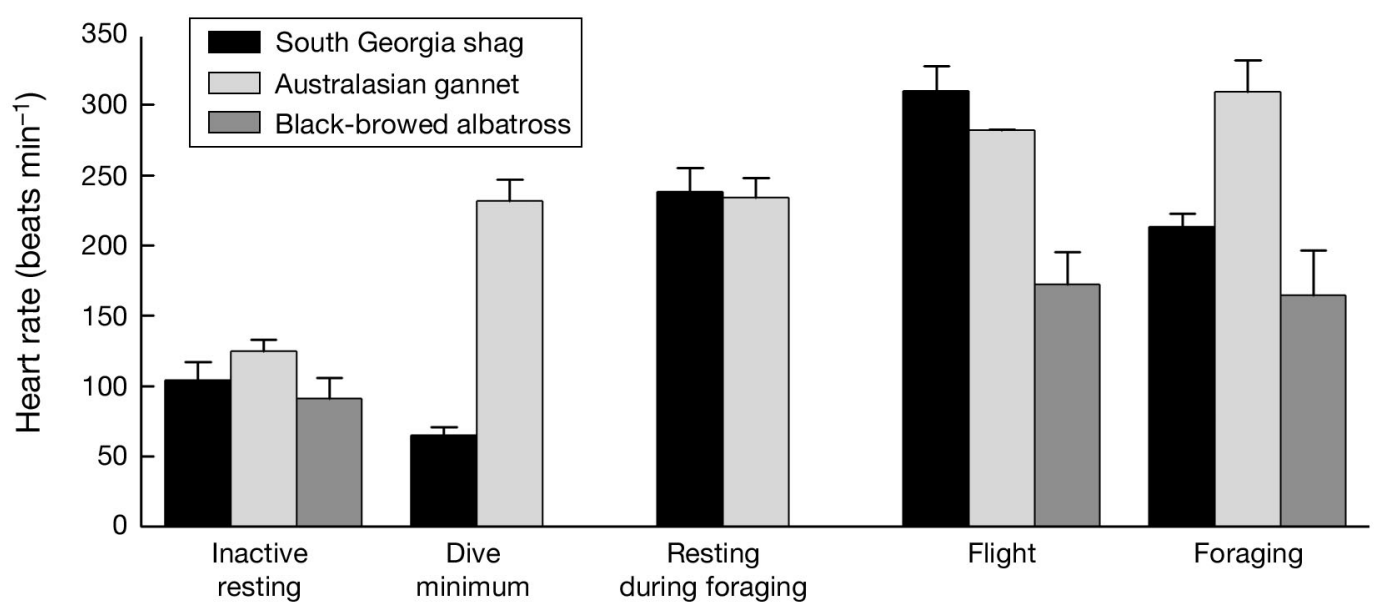

Fig. 4. Phalacrocorax georgianus, Morus serrator and Thalassarche melanophrys. Comparison of mean ( \pm SEM) activity-specific heart rates in 3 free-ranging seabirds: South Georgia shag (2.4 kg, Bevan et al. 1997) (black bars), Australasian gannet (2.5 kg, present study) (light grey bars), and black-browed albatross (3.6 kg, Bevan et al. 1995)(dark grey bars). Australasian gannets are plunge divers whereas South Georgia shags dive from the water surface. Black-browed albatrosses are generalist foragers from the water surface that do some diving. In the gannet, heart rate and therefore energetic costs of foraging are equivalent to those during flight. In the South Georgia shag, heart rate and therefore energetic costs of foraging are equivalent to those while resting during foraging, normally on the water surface. In the black-browed albatross, energetic costs of flight and foraging are also equivalent, but far less than in the Australasian gannet

tive resting. However, when compared to Australian gannets, this increase was relatively small. Blackbrowed albatrosses spend $\sim 70 \%$ of their foraging trips in dynamic soaring flight (Bevan et al. 1995).

Therefore, when compared to other diving modes, foraging by plunge diving in Australasian gannets indeed incurs a substantial energetic cost. The key driver of this high energetic cost is the necessity for the birds to be airborne in order to forage. As we have seen, the plunge dive itself is very brief, so the high cost of flight is the major component of the high cost of foraging. Furthermore, each time gannets undertake a dive, they must take off from the water surface to resume foraging. Of all the behaviours identified, takeoff had the highest $f_{\mathrm{H}}$ and thus the highest energetic cost (Table 1). Take-off has previously been shown to be the most demanding part of seabird flight, and the number of take-offs can have a significant impact on the total energy budget of seabirds (Weimerskirch et al. 2000, Shaffer et al. 2001).

Some simple calculations reveal that the high costs of foraging are offset by very high rates of energy gain during dives. If $50 \%$ of plunge dives were successful (Wanless et al. 2005) and a single prey item weighing 32.5 g (Bunce 2001) was caught during each successful dive, Australasian gannets would gain prey at a potential minimum rate of $287 \mathrm{~g}$ (min submerged) $)^{-1}$, given the mean dive duration of $3.4 \mathrm{~s}$ (Table 2). Varying the success rate of plunge dives from 25 to $75 \%$ would still give a range of 143 to $430 \mathrm{~g}$ (min submerged) $)^{-1}$. This catch per unit effort (CPUE) is up to 100 times greater than that reported for penguins (see Green et al. 2007 for summary) and 7 times greater than the highest CPUE reported so far among seabirds $(41 \mathrm{~g}$ (min submerged $)^{-1}$ for the great cormorant Phalacrocorax carbo (Grémillet et al. 2004). Recalculating data on the energetics and foraging behaviour of northern gannets Morus bassanus given by Enstipp et al. (2006) and Lewis et al. (2004) yields an even greater CPUE estimate of $776 \mathrm{~g}$ (min submerged) ${ }^{-1}$. In both cases, CPUE would be lower if the gannets were engaged in large amounts of surface foraging that we could not detect in the present study. However, except for populations that have become dependent on fishery discards as a food source, this is not thought to be a particularly important mode of foraging for gannets (Grémillet et al. 2008). We propose that by monitoring their foraging area from the air, gannets must be able to locate profitable prey patches, where their chance of catching large prey items with a high probability of success is maximised.

\section{Time allocation during seabird foraging}

All seabirds must balance the costs and benefits of foraging. Flapping flight is the most energetically expensive mode of animal locomotion (SchmidtNielsen 1972); thus, a foraging mode that depends on a high proportion of time spent in flapping flight will inevitably incur high energetic costs. It has been suggested that the mode of flight of gannets and boobies 
which features high frequency flap/glide cycles is energetically expensive (Ropert-Coudert et al. 2006). Studies estimating flight costs in plunge divers using doubly labelled water have both confirmed (BirtFriesen et al. 1989), and refuted (Ballance 1995) this suggestion. An interspecific comparison of time allocation among seabirds reveals some interesting patterns (Fig. 5). Surface divers, which tend to have a flapping style of flight, spend a low proportion of their foraging trips in flight but a large proportion submerged beneath the water surface searching for and consuming their prey. These species offset their high flight costs by minimising their flight time and are proficient deep divers. This is exemplified by penguins, which are flightless and are the most prodigious avian divers. Penguins swim between prey patches, incurring even lower energetic costs (Schmidt-Nielsen 1972). At the other end of the scale, occasional divers (more generalist predators that mix some diving with surface feeding) tend to use dynamic soaring (gliding) flight which has a low energetic cost (Bevan et al. 1995, Weimerskirch et al. 2000, Shaffer et al. 2001), and spend the majority of their foraging trips in flight. Plunge divers sit in the middle of this continuum. Indeed, there is substantial variation among species in the amount of time spent in flight. The larger/heavier gannets spend considerably less time in flight than the smaller/lighter boobies (Fig. 5). This is consistent with the estimates of flight costs in boobies (Ballance 1995) and gannets (Birt-Friesen et al. 1989) made using doubly labelled water. In combination, these data suggest that the high energetic cost of flight in gannets limits the amount of time that they can spend on foraging. Gannets spend up to $65 \%$ of their foraging trip sitting at the water surface (Fig. 5). Gannets cannot gain energy during this time, so something must be preventing them from either foraging further or returning to their breeding colony. It has been suggested that they use this time to recover from the high energy costs incurred during the first part of the trip, and to digest the food they have

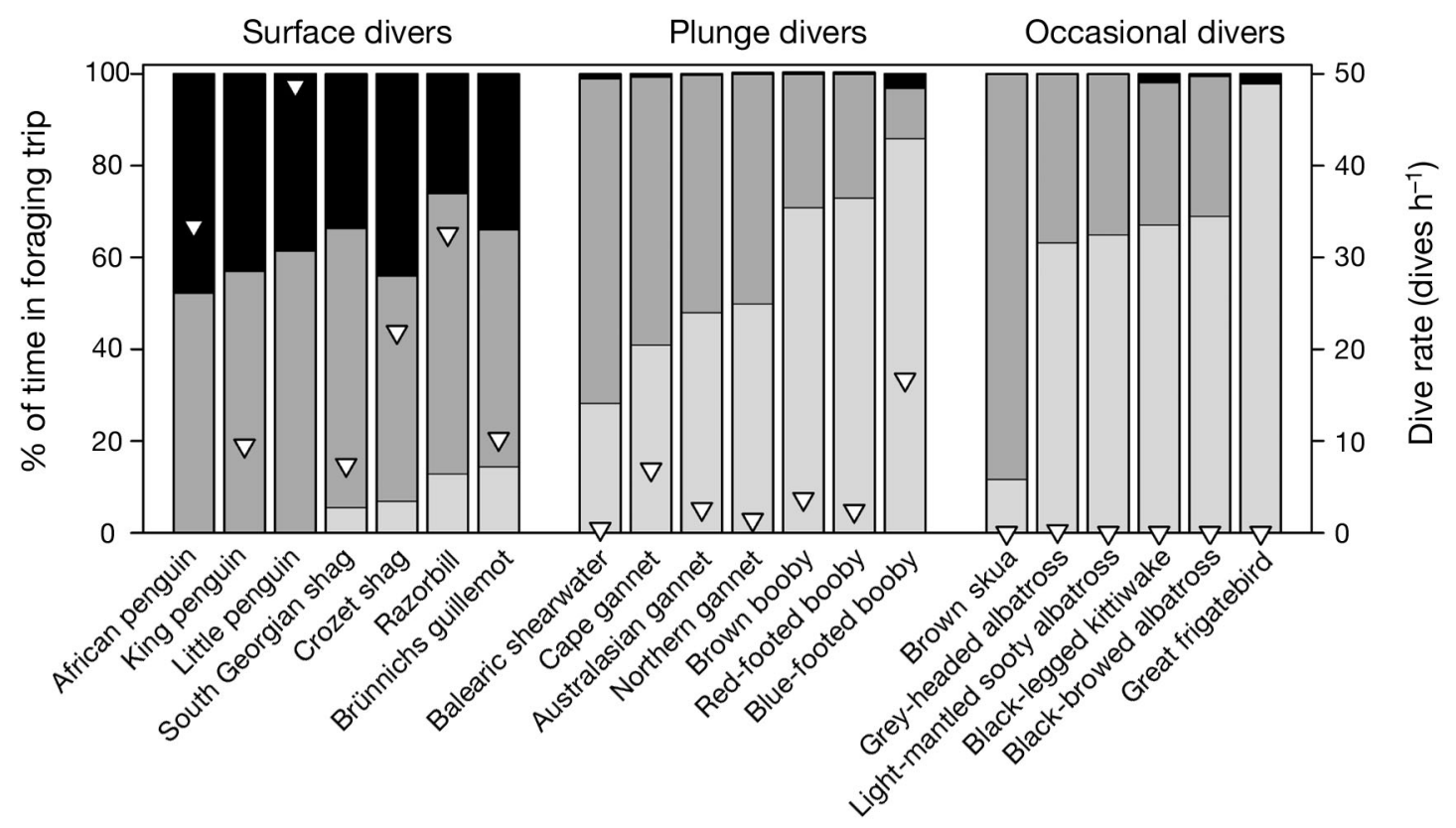

Fig. 5. Percentage time allocation during foraging trips by seabirds utilising 1 of 3 foraging modes: time spent in flight (light grey), time spent at the water surface (dark grey), and time submerged below the water (black). $(\nabla)$ Dive rate during foraging trips. Surface divers commence diving from the water surface, plunge divers dive from the air. Occasional divers are more generalist foragers whose strategy may involve surface dives, plunge dives, surface feeding or feeding on the wing (great frigatebird). Data presented are merely representative of the different foraging modes rather than an exhaustive list. Sources and species names for data in the figure: African penguin Spheniscus demersus (Petersen et al. 2006), king penguin Aptenodytes patagonicus (Pütz \& Cherel 2005), little penguin Eudyptula minor (Hoskins et al. 2008), South Georgia shag Phalacrocorax georgianus (Bevan et al. 1997), Crozet shag P. melanogenis (Tremblay et al. 2005), razorbill Alca torda (Dall'Antonia et al. 2001), Brünnich's guillemot Uria lomvia (Falk et al. 2000), Balearic shearwater Puffinus mauretanicus (Aguilar et al. 2003), Australasian gannet Morus serrator (present study), Cape gannet M. capensis (Ropert-Coudert et al. 2004a), northern gannet M. bassanus (Lewis et al. 2004, Garthe et al. 2007), brown booby Sula leucogaster (Lewis et al. 2005), red-footed booby S. sula (Lewis et al. 2005), blue-footed booby S. nebouxii (Zavalaga et al. 2007), brown skua Catharacta antarctica (Phillips et al. 2007), grey-headed albatross Thalassarche chrysostoma (Huin \& Prince 1997), light-mantled sooty albatross Phoebetria palpebrata (Phillips et al. 2005), black-legged kittiwake Rissa tridactyla (Daunt et al. 2002), black-browed albatross T. melanophris (Bevan et al. 1995) and great frigatebird 
captured during the trip, which minimises their flight costs by reducing the parasitic load of undigested food (Ropert-Coudert et al. 2004a). We conclude that remaining at the water surface between foraging bouts must be energetically more efficient than returning to the breeding colony, even though energetic costs while the birds are inactive (presumably on land) are lower (Table 1). In combination, these results support our hypothesis. When compared with other seabirds with different foraging modes, foraging is energetically expensive in gannets because energy expenditure during diving and flight is relatively high (Fig. 4), with a large time allocation to flight (Fig. 5) and long foraging trips (Enstipp et al. 2006). We propose that these high costs are offset by a reduced dive frequency, a high probability of prey capture and large energy gain per prey item.

\section{Behaviour and physiology within dives}

The hourly dive rate during foraging trips of Australasian gannets was less than the $6.4( \pm 1.2)$ dives $\mathrm{h}^{-1}$ recorded for the closely related Cape gannets Morus capensis (Ropert-Coudert et al. 2004b) but more than the $1.4( \pm 0.2)$ dives $\mathrm{h}^{-1}$ seen in northern gannets (Lewis et al. 2004). One of the Australasian gannets dived considerably less frequently than the other 3 (Table 2), but Cape and northern gannets also showed similarly high levels of inter-individual variation in dive frequency (Lewis et al. 2004, Ropert-Coudert et al. $2004 \mathrm{~b}$ ). The mean dive depths and duration of the Australasian gannets were slightly less than those of Cape gannets (Ropert-Coudert et al. 2004b). Maximum dive depth and duration were both $\sim 50 \%$ greater in Australasian than in Cape gannets. Mean dive depth and duration were both less than those in northern gannets (Garthe et al. 2000). $f_{\mathrm{H}}$ showed an unusual pattern of change within dives. During plunge diving, gannets use the momentum gained as they descend from the air to the water surface to reach their intended depth. This may be supplemented by additional wing flapping while at depth or during early ascent and/or a passive ascent (Garthe et al. 2000, Ropert-Coudert et al. 2004b). $f_{\mathrm{H}}$ decreased during descent and increased during the initial part of the ascent phase as commonly observed in diving animals (e.g. Green et al. 2003), but the subsequent decrease in $f_{\mathrm{H}}$ during the last part of the ascent phase is most unusual. The transient increase may be the result of additional underwater wing flapping by the birds in order to capture prey items or assist in ascent. Minimum $f_{\mathrm{H}}$ during dives decreased with increasing dive duration, as seen in other species of diving birds (e.g. Green et al. 2003). However, since nearly all dives were of very short duration, the mean minimum $f_{\mathrm{H}}$ during dives was not significantly different from the $f_{\mathrm{H}}$ while resting during foraging. This diving behaviour and physiology of the gannets is analogous to that of less well-adapted divers such as the tufted duck (Woakes \& Butler 1983) rather than to that of the most specialised divers such as penguins (Green et al. 2003), or shags (Fig. 4) in which the minimum $f_{\mathrm{H}}$ during dives usually falls below the resting $f_{\mathrm{H}}$ both on water and on land.

\section{Other activity-specific $\boldsymbol{f}_{\mathrm{H}}$}

In the present study, $f_{\mathrm{H}}$ while resting during foraging was nearly double that during inactive resting. Increases in $f_{\mathrm{H}}$ associated with moving from air to water have been observed in several species of freeranging seabirds and waterfowl, and usually reflect increased thermoregulatory costs associated with the far greater conductivity of water (Butler 2000). In the present study, the birds might not have been on the water surface during periods of resting while foraging. They might have flown onto rocks or man-made structures, have been paddling or preening, or have an increased metabolism due to specific dynamic action (SDA). As mentioned in 'Discussion: Energetic costs of foraging diving', they might even have been engaged in surface foraging. The closely related Cape gannet actually showed no change in $f_{\mathrm{H}}$ while standing at their nests $\left(215 \pm 20\right.$ beats $\left.\mathrm{min}^{-1}\right)$ and when resting on the water surface $\left(209 \pm 11\right.$ beats $\left.\mathrm{min}^{-1}\right)$, although the $f_{\mathrm{H}}$ during each activity were more similar to those recorded in Australasian gannets that were resting on water (Ropert-Coudert et al. 2006). As suggested by Ropert-Coudert et al. (2006), the Cape gannets might not have been at rest, as measurements were taken shortly after deployment of multiple devices. While handling was kept to a minimum and lasted only 10 to $20 \mathrm{~min}$ in the latter study, gannets can very quickly become hot and agitated with raised body temperature after this amount of handling, particularly in warm conditions (J. A. Green unpubl. obs.). Mean $f_{\mathrm{H}}$ during flight in Australasian gannets was $281 \pm 1$ beats min $^{-1}$, which is similar to that recorded by Ropert-Coudert et al. (2006) during flapping flight in Cape gannets (250 \pm 46 beats $\min ^{-1}$ ) but greater than that recorded during gliding $\left(217 \pm 17\right.$ beats $\left.\mathrm{min}^{-1}\right)$. The difference in $f_{\mathrm{H}}$ between gliding and flapping flight was relatively small in Cape gannets, certainly when compared to similar sized flying barnacle geese Branta leucopsis (Butler \& Woakes 1980). However, the soaring/gliding phase of flight shown by geese lasted far longer (52 s) than the very short gliding intervals of just a few seconds shown by Cape gannets (Ropert-Coudert et al. 2006). Flight in gannets appears to be a high frequency 
combination of flapping and gliding periods, although the percentage of time spent gliding is lower during foraging flight (Ropert-Coudert et al. 2006).

Acknowledgements. We thank T. Pyk for assistance in the field and E. Aitken-Simpson for assistance in preliminary data analysis and for comments on the manuscript. This work was funded by the Deakin University Central Research Grant Scheme. C.R.W. was supported by a Natural Environment Research Council grant (NER/A/2003/00542) to G. R. Martin, A. J. Woakes and P.J.B. P.J.B. is a Visiting Distinguished Professor at La Trobe University.

\section{LITERATURE CITED}

Aguilar JS, Benvenuti S, Dall'Antonia L, McMinn-Grivé M, Mayol-Serra J (2003) Preliminary results on the foraging ecology of Balearic shearwaters (Puffinus mauretanicus) from bird-borne data loggers. Sci Mar 67:129-134

Ballance LT (1995) Flight energetics of free-ranging redfooted boobies (Sula sula). Physiol Zool 68:887-914

Berrow SD, Wood AG, Prince PA (2000) Foraging location and range of white-chinned petrels Procellaria aequinoctialis breeding in the South Atlantic. J Avian Biol 31:303-311

Bevan RM, Woakes AJ, Butler PJ, Boyd IL (1994) The use of heart rate to estimate oxygen consumption of free-ranging black-browed albatrosses Diomedea melanophrys. J Exp Biol 193:119-137

Bevan RM, Butler PJ, Woakes AJ, Prince PA (1995) The energy expenditure of free-ranging black-browed albatrosses. Philos Trans R Soc Lond B Biol Sci 350:119-131

Bevan RM, Boyd IL, Butler PJ, Reid K, Woakes AJ, Croxall JP (1997) Heart rates and abdominal temperatures of freeranging South Georgian shags, Phalocrocorax georgianus. J Exp Biol 200:661-675

Birt-Friesen VL, Montevecchi WA, Cairns DK, Macko SA (1989) Activity-specific metabolic rates of free-living northern gannets and other seabirds. Ecology 70:357-367

Bunce A (2001) Prey consumption of Australasian gannets (Morus serrator) breeding in Port Philip Bay, southeast Australia, and potential overlap with commercial fisheries. ICES J Mar Sci 58:904-915

Butler PJ (1993) To what extent can heart rate be used as an indicator of metabolic rate in free-living marine mammals? Symp Zool Soc Lond 66:317-332

Butler PJ (2000) Energetic costs of surface swimming and diving of birds. Physiol Biochem Zool 73:699-705

Butler PJ, Woakes AJ (1980) Heart rate respiratory frequency and wing beat frequency of free flying barnacle geese Branta leucopsis. J Exp Biol 85:213-226

> Catry P, Phillips RA, Phalan B, Silk JRD, Croxall JP (2004) Foraging strategies of grey-headed albatrosses Thalassarche chrysostoma: integration of movements, activity and feeding events. Mar Ecol Prog Ser 280:261-273

> Chaurand T, Weimerskirch H (1994) The regular alternation of short and long foraging trips in the blue petrel Halobaena caerulea: a previously undescribed strategy of food provisioning in a pelagic seabird. J Anim Ecol 63: $275-282$

> Dall'Antonia L, Gudmonsson GA, Benvenuti S (2001) Time allocation and foraging pattern of chick-rearing razorbills in northwest Iceland. Condor 103:469-480

> Daunt F, Benvenuti S, Harris MP, Dall'Antonia L, Elston DA, Wanless S (2002) Foraging strategies of the black-legged kittiwake Rissa tridactyla at a North Sea colony: evidence for a maximum foraging range. Mar Ecol Prog Ser 245: $239-247$

Enstipp MR, Grémillet D, Lorentsen SH (2005) Energetic costs of diving and thermal status in European shags (Phalacrocorax aristotelis). J Exp Biol 208:3451-3461

Enstipp MR, Daunt F, Wanless S, Humphreys EM, Hamer KC, Benvenuti S, Grémillet D (2006) Foraging energetics of North Sea birds confronted with fluctuating prey availability. In: Boyd IL, Wanless S, Camphuysen CJ (eds) Top predators in marine ecosystems. Cambridge University Press, Cambridge, p 191-210

Falk K, Benvenuti S, Dall'Antonia L, Kampp K, Ribolini A (2000) Time allocation and foraging behaviour of chickrearing Brünnich's guillemots Uria lomvia in high-arctic Greenland. Ibis 142:82-92

Fick A (1870) Über die Messung des Blutquantums in den Herzventrikeln. Sitz Physik Med Ges 2:16

Garthe S, Benvenuti S, Montevecchi WA (2000) Pursuit plunging by northern gannets (Sula bassana) feeding on capelin (Mallotus villosus). Proc R Soc Lond B 267:1717-1722

> Garthe S, Montevecchi WA, Chapdelaine G, Rail JF, Hedd A (2007) Contrasting foraging tactics by northern gannets (Sula bassana) breeding in different oceanographic domains with different prey fields. Mar Biol 151:687-694

Green JA, Butler PJ, Woakes AJ, Boyd IL, Holder RL (2001) Heart rate and rate of oxygen consumption of exercising macaroni penguins. J Exp Biol 204:673-684

Green JA, Butler PJ, Woakes AJ, Boyd IL (2002) Energy requirements of female macaroni penguins breeding at South Georgia. Funct Ecol 16:671-681

Green JA, Butler PJ, Woakes AJ, Boyd IL (2003) Energetics of diving in macaroni penguins. J Exp Biol 206:43-57

Green JA, Tanton JL, Woakes AJ, Boyd IL, Butler PJ (2004) Effects of long-term implanted data loggers on macaroni penguins. J Avian Biol 35:370-376

Green JA, Boyd IL, Woakes AJ, Green CJ, Butler PJ (2007) Feeding, fasting and foraging success during chick-rearing in macaroni penguins. Mar Ecol Prog Ser 346: 299-312

Grémillet D, Kuntz G, Delbart F, Mellet M and others (2004) Linking the foraging performance of a marine predator to local prey abundance. Funct Ecol 18:793-801

Grémillet D, Kuntz G, Woakes AJ, Gilbert C, Robin JP, Le Maho Y, Butler PJ (2005) Year-round recordings of behavioural and physiological parameters reveal the survival strategy of a poorly insulated diving endotherm during the Arctic winter. J Exp Biol 208:4231-4241

> Grémillet D, Pichegru L, Kuntz G, Woakes AJ, Wilkinson S, Crawford RJM, Ryan PG (2008) A junk-food hypothesis for gannets feeding on fishery waste. Proc R Soc Lond B 275: 1149-1156

Guillemette M, Woakes AJ, Flagstad A, Butler PJ (2002) Effects of data-loggers implanted for a full year in female common eiders. Condor 104:448-452

Guillemette M, Woakes AJ, Henaux V, Grandbois JM, Butler PJ (2004) The effect of depth on the diving behaviour of common eiders. Can J Zool 82:1818-1826

> Hoskins AJ, Dann P, Ropert-Coudert Y, Kato A, Chiaradia A, Costa DP, Arnould JPY (2008) Foraging behaviour and habitat selection of the little penguin Eudyptula minor during early chick rearing in Bass Strait, Australia. Mar Ecol Prog Ser 366:293-303

> Huin N, Prince PA (1997) Diving behaviour of the greyheaded albatross. Antarct Sci 9:243-249

> Krueger C, Tian L (2004) A comparison of the general linear mixed model and repeated measures ANOVA using a dataset with multiple missing points. Biol Res Nurs 6: $151-157$ 
Lewis S, Benvenuti S, Daunt F, Wanless S and others (2004) Partitioning of diving effort in foraging trips of northern gannets. Can J Zool 82:1910-1916

Lewis S, Schreiber EA, Daunt F, Schenk GA and others (2005) Sex-specific foraging behaviour in tropical boobies: Does size matter? Ibis 147:408-414

Pelletier D, Guillemette M, Grandbois JM, Butler PJ (2007) It is time to move: linking flight and foraging behaviour in a diving bird. Biol Lett 3:357-359

Petersen SL, Ryan PG, Gremillet D (2006) Is food availability limiting African penguins Spheniscus demersus at Boulders? A comparison of foraging effort at mainland and island colonies. Ibis 148:14-26

Phillips RA, Silk JRD, Croxall JP (2005) Foraging and provisioning strategies of the light-mantled sooty albatross at South Georgia: competition and co-existence with sympatric pelagic predators. Mar Ecol Prog Ser 285:259-270

Phillips RA, Catry P, Silk JRD, Bearhop S, McGill R, Afanasyev V, Strange IJ (2007) Movements, winter distribution and activity patterns of Falkland brown skuas: insights from loggers and isotopes. Mar Ecol Prog Ser 345:281-291

> Pütz K, Cherel Y (2005) The diving behaviour of brooding king penguins (Aptenodytes patagonicus) from the Falkland Islands: variation in dive profiles and synchronous underwater swimming provide new insights into their foraging strategies. Mar Biol 147:281-290

Ropert-Coudert Y, Grémillet D, Kato A, Ryan PG, Naito Y, Le Maho Y (2004a) A fine-scale time budget of Cape gannets provides insights into the foraging strategies of coastal seabirds. Anim Behav 67:985-992

Ropert-Coudert Y, Grémillet D, Ryan P, Kato A, Naito Y, Le Maho Y (2004b) Between air and water: the plunge dive of the Cape gannet Morus capensis. Ibis 146:281-290

Ropert-Coudert Y, Wilson RP, Grémillet D, Kato A, Lewis S, Ryan PG (2006) Electrocardiogram recordings in freeranging gannets reveal minimum difference in heart rate during flapping versus gliding flight. Mar Ecol Prog Ser 328:275-284

Sato K, Watanuki Y, Takahashi A, Miller PJO and others (2007) Stroke frequency, but not swimming speed, is related to body size in free-ranging seabirds, pinnipeds and cetaceans. Proc R Soc Lond B 274:471-477

Editorial responsibility: Clive McMahon,

Darwin, Northern Territory, Australia
Schmidt-Nielsen K (1972) Locomotion: energy cost of swimming, flying, and running. Science 177:222-228

Shaffer SA, Costa DP, Weimerskirch H (2001) Behavioural factors affecting foraging effort of breeding wandering albatrosses. J Anim Ecol 70:864-874

- Stephenson R, Butler PJ, Woakes AJ (1986) Diving behaviour and heart rate in tufted ducks Aythya fuligula. J Exp Biol 126:341-359

> Tremblay Y, Cook TR, Cherel Y (2005) Time budget and diving behaviour of chick-rearing Crozet shags. Can J Zool 83:971-982

Wanless S, Harris MP, Morris JA (1995) Factors affecting daily activity budgets of South Georgian shags during chick rearing at Bird Island, South Georgia. Condor 97:550-558

Wanless S, Daunt F, Camphuysen CJK, Hamer KC and others (2005) Setting the scene (3): colony based and at-sea data on seabirds. In: Camphuysen CJK (ed) Understanding marine foodweb processes: an ecosystem approach to sustainable sand eel fisheries in the North Sea. IMPRESS, Interactions between the marine environment, predators and prey: implications for sustainable sandeel fisheries Final Report QRRS 2000-30864, p 88-134

- Ward S, Bishop CM, Woakes AJ, Butler PJ (2002) Heart rate and the rate of oxygen consumption of flying and walking barnacle geese (Branta leucopsis) and bar-headed geese (Anser indicus). J Exp Biol 205:3347-3356

> Weimerskirch H, Le Corre M, Jaquemet S, Potier M, Marsac F (2004) Foraging strategy of a top predator in tropical waters: great frigatebirds in the Mozambique Channel. Mar Ecol Prog Ser 275:297-308

> Weimerskirch H, Guionnet T, Martin J, Shaffer SA, Costa DP (2000) Fast and fuel efficient? Optimal use of wind by flying albatrosses. Proc R Soc Lond B 267:1869-1874

> Weimerskirch H, Martin J, Clerquin Y, Alexandre P, Jiraskova S (2001) Energy saving in flight formation. Nature 413:697-698

Woakes AJ, Butler PJ (1983) Swimming and diving in tufted ducks, Aythya fuligula, with particular reference to heart rate and gas exchange. J Exp Biol 107:311-329

Zavalaga CB, Benvenuti S, Dall'Antonia L, Emslie SD (2007) Diving behavior of blue-footed boobies Sula nebouxii in northern Peru in relation to sex, body size and prey type. Mar Ecol Prog Ser 336:291-303

Submitted: March 6, 2009; Accepted: July 21, 2009

Proofs received from author(s): October 22, 2009 